\section{Medizin mit Durchblick: Das \\ Patientenmagazin der DRG jetzt online bestellen}

Im Mai 2013 ist die Deutsche Röntgengesellschaft (DRG) mit der Zeitschrift Medizin mit Durchblick an den Start gegangen - ein Magazin, das speziell auf die Interessen von Patienten zugeschnitten ist. Radiologische Kliniken und Praxen legen die Zeitschrift in ihren Wartezimmern aus, um ihren Patienten die Zeit zu verkürzen und gleichzeitig die Inhalte und einige $\mathrm{Ge}$ heimnisse der Radiologie zu vermitteln.

Ab sofort ist das Heft ab einer Menge von 10 Exemplaren über ein Onlinebestellsystem via www.drg.de bestellbar. Es ist ganz einfach: Sie geben die gewünschte Menge sowie Ihre Kontaktdaten an. Wir schicken Ihnen eine Rechnung zu. Sie begleichen, und wir senden Ihnen die Exemplare zu.

Das Heft ist im November 2013 in die 2. Runde gegangen und greift dieses Mal die Themen Schlaganfall, Kinderradiologie und den MTRA-Beruf auf. Die 2. Auflage wurde verdoppelt - dank des Erfolgs des ersten Hefts und wegen der Kooperation mit dem Lesezirkel, wodurch die Magazine auch in Physiotherapiepraxen, Geschäften und Privathaushalten verteilt werden.

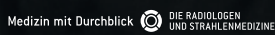

Medizin mit Durchblick Das Radiologie-Magazin für Patienter

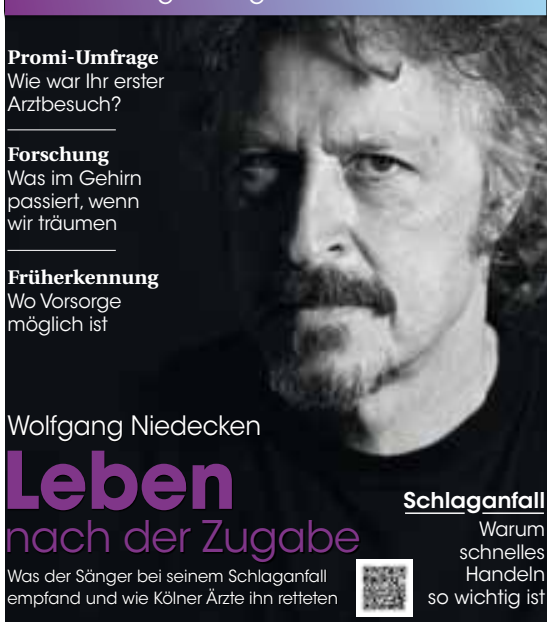

